\title{
Monocyte chemoattractant protein 1 expression and proliferation in primary central nervous system lymphoma
}

\author{
YOSHINOBU TAKAHASHI ${ }^{1,2}$, TAKAHIRO SAWADA ${ }^{2}$, TOSHIAKI AKAHANE $^{3}$, \\ YUMIKO KAWASE ${ }^{2}$, HIDETOSHI IKEDA ${ }^{4}$, KEISHI MAKINO ${ }^{5}$, HIDEO NAKAMURA ${ }^{5}$, \\ TAKUICHIRO HIDE $^{5}$, SHIGETOSHI YANO ${ }^{5}$, NAOYA HASHIMOTO ${ }^{6}$ and HAJIME KAMADA ${ }^{1}$ \\ Departments of ${ }^{1}$ Neurosurgery, ${ }^{2}$ Cancer Biology and Genetics, and ${ }^{3}$ Pathology, Hokuto Hospital, Obihiro, \\ Hokkaido 080-0033; ${ }^{4}$ Department of Neurosurgery, Osaka City General Hospital, Osaka 534-0021; \\ ${ }^{5}$ Department of Neurosurgery, Graduate School of Medical Science, Kumamoto University, Kumamoto 860-8556; \\ ${ }^{6}$ Department of Neurosurgery, Kyoto Prefectural University of Medicine, Kyoto 602-8566, Japan
}

Received September 2, 2016; Accepted March 9, 2017

DOI: 10.3892/ol.2017.6122

\begin{abstract}
Whether the poor prognosis of primary central nervous system lymphoma (PCNSL) compared with systemic diffuse large $\mathrm{B}$ cell lymphoma (DLBCL) is attributable to the immune privilege of the intracerebral location or to intrinsic differences in the biological characteristics of two types of lymphoma remains unclear. Monocyte chemoattractant protein 1 (MCP-1) is essential to support tumor cell survival and growth, and the present study aimed to compare MCP-1 expression in PCNSL and peripheral DLBCL. The present study included 19 patients with PCNSL and 16 patients with DLBCL, all of whom had tissue diagnosis and lymphoma tissue samples available for analysis. Histology included immunohistochemistry using antibodies against a panel of lymphoma markers, antibodies specific to MCP-1, and antibodies specific to tumor-associated macrophages. MCP-1 expression was quantified using immunostaining scoring. RNA extraction and reverse transcription-quantitative polymerase chain reaction were used to determine $M C P-1$ mRNA expression. In addition, a human brain-derived lymphoma cell line, HKBML, was stimulated with MCP-1 and cell proliferation was measured by 5-bromo-2'-deoxyuridine incorporation. The expression levels of $M C P-1$ mRNA and MCP-1 protein were significantly increased in PCNSL compared with peripheral DLBCL. MCP-1 induced tyrosine phosphorylation of mitogen-activated protein kinase in HKBML cells, as analyzed by western blotting. The results of the present study indicated that MCP-1 expression in PCNSL promoted cell proliferation in an autocrine manner.
\end{abstract}

Correspondence to: Dr Yoshinobu Takahashi, Department of Neurosurgery, Hokuto Hospital, 7-5 Inada, Obihiro, Hokkaido 080-0033, Japan

E-mail: yosinobu@hokuto7.or.jp

Key words: primary central nervous system lymphoma, monocyte chemoattractant protein 1 , autocrine, proliferation

\section{Introduction}

The incidence of primary central nervous system (CNS) lymphoma (PCNSL), defined as diffuse large B cell lymphoma (DLBCL) confined to the CNS, has reportedly increased in the immunocompetent population (1). It is not possible to morphologically distinguish PCNSL and peripheral DLBCL. High-dose methotrexate-based chemotherapy is the standard therapy for PCNSL. Chemotherapy with whole brain radiation therapy has produced response rates up to $80-90 \%$, and median overall survival up to 5 years. However, PCNSL has a poor prognosis compared with that of DLBCL (2) and the reason for difference in prognosis between PCNSL and DLBCL has not been elucidated.

Multiple leukocytes, including macrophages, are known to be present in tumor tissues. Among the inflammatory cells, tumor-associated macrophages (TAMs) are thought to directly or indirectly promote tumor progression (3-5). TAMs are divided into two categories: M1 macrophages, also known as classically activated macrophages; and M2 macrophages, frequently referred to as alternatively activated macrophages. In malignant tumors, TAMs that have differentiated into M2 macrophages act as protumoral macrophages and contribute to disease progression (6). Previous studies have demonstrated that higher levels of M2-polarized TAMs are associated with a worse prognosis in various tumors, including glioma $(7,8)$, renal cell cancer (9) and T-cell leukemia/lymphoma (10). Certain reports concerning DLBCL have indicated that TAMs are associated with a worse clinical course (11), but others have suggested that TAMs are not associated with overall survival $(12,13)$. On the other hand, TAM infiltration has no prognostic value in PCNSL $(14,15)$. The reason for this remains unclear.

Monocyte chemoattractant protein (MCP-1), also known as $\mathrm{C}-\mathrm{C}$ motif chemokine ligand 2 , is a member of a superfamily of cytokines known as chemokines. C-C motif chemokine receptor 2 (CCR2) is the major receptor for MCP-1, and its binding activates a series of downstream signaling pathways including p42/44 mitogen-activated protein kinase 
(MAPK), phospholipase $\mathrm{C}-\gamma$ and protein kinase $\mathrm{C}$ through $\mathrm{G}$ protein-dependent mechanisms to regulate cellular adhesion and motility in macrophages (16-18). This binding recruits TAMs (19). In several types of cancer, MCP-1 has been demonstrated to be an important determinant of tumor growth (20-22). MCP-1 is primarily produced by neoplastic $\mathrm{B}$ cells, and less frequently by lesional reactive astrocytes in primary CNS lymphoma (23). However, the involvement of MCP-1 has not been elucidated in PCNSL.

The aim of the present study was to determine whether MCP-1 expression and TAM infiltration differ between PCNSL and DLBCL. The relationship between MCP-1 expression and the proliferation of tumor cells in PCNSL was also investigated.

\section{Materials and methods}

Patients. The present study included 19 patients with PCNSL and 16 patients with DLBCL. Patients were treated at Hokuto Hospital (Obihiro, Japan) and Kumamoto University Hospital (Kumamoto, Japan) between January 2008 and December 2013. Laboratory examinations were negative for acquired immunodeficiency syndrome in all patients. Informed written consent was obtained from all patients from each hospital, and the present study was approved by the Ethics Committee of Hokuto Hospital (Obihiro, Japan). Histopathological diagnosis of malignant lymphoma (diffuse large B cell type) was confirmed with each author. The analyses of each patient in the present study are summarized in Table I.

RNA extraction, reverse transcription-quantitative polymerase chain reaction ( $R T-q P C R$ ). In total, 16 specimens with PCNSL and 13 specimens with DLBCL were adequate for RNA extraction. Formalin-fixed paraffin-embedded sections were deparaffinized using Paraffin Dissolver (Machery-Nagel GmbH, Düren, Germany; cat. no. 740968.25), according to the manufacturer's instruction. For preparation of total RNA from tumors, the MasterPure RNA Purification kit (Epicentre; Illumina, Inc., San Diego, CA, USA; cat. no. MCR85102) was used according to the manufacturer's protocol. cDNA was synthesized from total RNA using the High-Capacity cDNA Reverse Transcription kit (Applied Biosystems; Thermo Fisher Scientific, Inc., Waltham, MA, USA). The cDNA (50-60 ng) was used for qPCR analyses via TaqMan Gene Expression Assays (Applied Biosystems; Thermo Fisher Scientific, Inc.) for MCP-1 (prove ID: Hs0023410_m1; Applied Biosystems; Thermo Fisher Scientific, Inc.). PCR was conducted using the Applied Biosystems 7900HT Fast Real-Time PCR System (Applied Biosystems; Thermo Fisher Scientific, Inc.). The real-time PCR conditions were $5 \mathrm{~min}$ at $95^{\circ} \mathrm{C}$ followed by 40 cycles at $95^{\circ} \mathrm{C}$ for $15 \mathrm{sec}$ and $60^{\circ} \mathrm{C}$ for $1 \mathrm{~min}$. Ribosomal RNA (prove ID: Hs99999901_s1; Applied Biosystems; Thermo Fisher Scientific, Inc.) served as the reference gene. The relative quantification (RQ) method was applied to determine gene expression levels. Values of RQ within the range ( $\mathrm{RQ} \pm 2$ standard deviations) of the corresponding reference group were accepted as normal. Threshold cycle $\left(C_{q}\right)$ values were automatically calculated for each replicate and used to determine the expression of the gene of interest relative to that of the reference gene for treated and untreated samples using the $2^{-\Delta \Delta C q}$ method (24).

Immunohistochemistry. Formalin-fixed, paraffin-embedded tissues were sectioned (4- $\mu \mathrm{m}$-thick). Antigen epitopes were heat-retrieved in ImmunoSaver ${ }^{\mathrm{TM}}$ (Nissin EM Ltd., Tokyo, Japan) at $98^{\circ} \mathrm{C}$ for $45 \mathrm{~min}$. The samples were stained using the following antibodies: MCP-1 (1:200; Abcam, Cambridge, UK; cat. no. ab7202); cluster of differentiation (CD)14 (1:100; Abcam; cat. no. ab183322); and CD68 (supplied at working dilution; Nichirei Biosciences Inc. Tokyo, Japan; cat. no. 413791). The samples were incubated with each antibody at room temperature for $1 \mathrm{~h}$. The intensity scores were as follows: 0 , negative; 1 , weakly positive; 2 , moderately positive and 3 , strongly positive. The proportional scores were as follows: $0 \% ; 1,1-10 \% ; 2,11-50 \%$ and $3,51-100 \%$. Using a total score (intensity score + proportional score), immunohistochemical positivity was classified as negative (0), total score $=0$; weakly positive $(+1)$, total score $=1,2$; moderately positive $(+2)$, total score $=3,4$; or strongly positive $(+3)$, total score $=5,6$. These criteria were determined by one of the co-authors who was blinded with respect to the clinical data. The relative number of positive cells and the intensity of staining were assessed in five random fields under a light microscope and magnification x200.

CCR2 and CD20, a B cell marker, were examined by immunofluorescent double staining. For double staining with two monoclonal antibodies, the cells were first incubated in CD20 antibody (1:400; Dako; Agilent Technologies, Inc., Santa Clara, CA, USA; cat. no. M0755) at room temperature for $1 \mathrm{~h}$, followed by the CCR2 antibody (1:100; Abcam; cat. no. ab32144 at room temperature for $1 \mathrm{~h}$. Anti-mouse immunoglobulin (Ig)G (heavy and light chain; $\mathrm{H}+\mathrm{L}$ ), $\mathrm{F}(\mathrm{ab})_{2}$ fragment (Alexa Fluor ${ }^{\mathrm{R}} 555$ conjugate; 1:1,000; Cell Signaling Technology, Inc., Danvers, MA, USA; cat. no. 4409) and anti-rabbit IgG $(\mathrm{H}+\mathrm{L}), \mathrm{F}(\mathrm{ab})_{2}$ Fragment (Alexa Fluor ${ }^{\mathrm{R}} 488$ conjugate; 1:1,000; Cell Signaling Technology, Inc.; cat. no. 4412) were used as secondary antibodies at room temperature for $1 \mathrm{~h}$. Confocal fluorescence images (magnification, $\mathrm{x} 400$ ) were confirmed on a Carl Zeiss confocal system (Zeiss $\mathrm{GmbH}$, Jena, Germany) in 10 random fields by two of the co-authors.

Cell culture. The human brain-derived lymphoma cell line, HKBML (Riken BioResource Center, Tsukuba, Japan), was maintained in Ham's nutrient mixture F-12 medium (Sigma-Aldrich; KGaA, Darmstadt, Germany; cat. no. N6658) supplemented with $15 \%$ fetal bovine serum and penicillin-streptomycin, and incubated in a $37^{\circ} \mathrm{C}, 5 \% \mathrm{CO}_{2}$ and a humidified atmosphere. Prior to stimulation with 0 , 250,500 or $1,000 \mathrm{ng} / \mathrm{ml} \mathrm{MCP}-1$, the cells were preincubated in F-12 medium containing $0.5 \%$ fetal bovine serum overnight. HKBML proliferation activity was measured by 5-bromo-2'-deoxyuridine (BrdU) incorporation into the cells, which were plated as floating single cells at $2 \times 10^{4}$ cells per well onto 96 well plates. Following a 3 day incubation with MCP-1, $\mathrm{BrdU}(10 \mu \mathrm{M})$ was added for $2 \mathrm{~h}$ at $37^{\circ} \mathrm{C}$ and in a $5 \% \mathrm{CO}_{2}$ humidified atmosphere, using the Cell Proliferation ELISA kit (Roche Diagnostics, Basel, Switzerland; cat. no. 11647229001), according to the 
Table I. Summary of analyses of patients with PCNSL and DLBL.

\begin{tabular}{|c|c|c|c|c|c|c|c|}
\hline \multirow[b]{2}{*}{ Type of cancer } & \multirow[b]{2}{*}{ Case } & \multirow[b]{2}{*}{ Age } & \multirow[b]{2}{*}{ Sex } & \multirow{2}{*}{$\begin{array}{l}\text { RT-qPCR (MCP-1; } \\
\text { arbitrary unit) }\end{array}$} & \multicolumn{3}{|c|}{ Immunostaining score } \\
\hline & & & & & MCP-1 & CD14 & CD68 \\
\hline \multirow[t]{19}{*}{ PCNSL } & $\mathrm{P} 1$ & 71 & $\mathrm{~F}$ & 18.6 & 3 & 3 & 2 \\
\hline & P2 & 62 & $\mathrm{M}$ & 4.3 & 2 & 3 & 2 \\
\hline & P3 & 73 & $\mathrm{~F}$ & 29.3 & 3 & 3 & 1 \\
\hline & $\mathrm{P} 4$ & 84 & $\mathrm{M}$ & 9.9 & 1 & 2 & 2 \\
\hline & P5 & 83 & $\mathrm{M}$ & 3.2 & 3 & 3 & 2 \\
\hline & P6 & 66 & $\mathrm{M}$ & 7.1 & 3 & 3 & 2 \\
\hline & P7 & 71 & $\mathrm{M}$ & NA & 2 & 2 & 2 \\
\hline & P8 & 85 & $\mathrm{~F}$ & 5.4 & 2 & 3 & 1 \\
\hline & P9 & 50 & $\mathrm{M}$ & 6.5 & 3 & 1 & NA \\
\hline & $\mathrm{P} 10$ & 64 & $\mathrm{~F}$ & NA & 2 & 3 & NA \\
\hline & P11 & 49 & $\mathrm{M}$ & 4.5 & 0 & 0 & NA \\
\hline & P12 & 80 & $\mathrm{~F}$ & 39.5 & 3 & 0 & NA \\
\hline & P13 & 71 & $\mathrm{~F}$ & 29.1 & 1 & 1 & NA \\
\hline & P14 & 80 & $\mathrm{~F}$ & NA & 3 & 1 & NA \\
\hline & P15 & 44 & $\mathrm{~F}$ & 57.6 & 1 & 1 & NA \\
\hline & P16 & 64 & $\mathrm{M}$ & 18.5 & NA & NA & NA \\
\hline & $\mathrm{P} 17$ & 49 & $\mathrm{M}$ & 1.1 & 3 & 3 & NA \\
\hline & P18 & 76 & $\mathrm{M}$ & 17.4 & 3 & 3 & NA \\
\hline & P19 & 81 & $\mathrm{~F}$ & 12.1 & 3 & 3 & NA \\
\hline \multirow[t]{16}{*}{ DLBCL } & D1 & 71 & $\mathrm{M}$ & 4.6 & 1 & 3 & 2 \\
\hline & D2 & 77 & $\mathrm{M}$ & 5.0 & 1 & 3 & 3 \\
\hline & D3 & 65 & $\mathrm{M}$ & NA & 1 & 0 & 1 \\
\hline & D4 & 75 & $\mathrm{~F}$ & 1.0 & 2 & 1 & 1 \\
\hline & D5 & 69 & $\mathrm{M}$ & 4.9 & 2 & 1 & 2 \\
\hline & D6 & 79 & $\mathrm{M}$ & NA & 0 & 1 & 3 \\
\hline & D7 & 61 & $\mathrm{~F}$ & 3.6 & 1 & 0 & 2 \\
\hline & D8 & 86 & $\mathrm{M}$ & 4.1 & 0 & 1 & 1 \\
\hline & D9 & 56 & $\mathrm{~F}$ & 2.8 & NA & 1 & NA \\
\hline & D10 & 66 & $\mathrm{M}$ & 1.2 & NA & 1 & NA \\
\hline & D11 & 69 & $\mathrm{M}$ & 1.3 & NA & 2 & NA \\
\hline & D12 & 76 & $\mathrm{M}$ & NA & NA & 3 & NA \\
\hline & D13 & 83 & $\mathrm{M}$ & 4.5 & NA & 3 & NA \\
\hline & D14 & 92 & $\mathrm{M}$ & 2.9 & NA & 3 & NA \\
\hline & D15 & 82 & $\mathrm{M}$ & 4.2 & NA & 2 & NA \\
\hline & D16 & 58 & $\mathrm{~F}$ & 1.1 & NA & 3 & NA \\
\hline
\end{tabular}

PCNSL, primary central nervous lymphoma; DLBCL, diffuse large B cell lymphoma; M, male; F, female; MCP-1, monocyte chemoattractant protein 1; RT-qPCR: reverse transcription-quantitative polymerase chain reaction, NA, not analyzed.

manufacturer's instruction. The media and no cells was used as a negative control.

Western blotting. Cells were lysed for western blotting following stimulation with $300 \mathrm{ng} / \mathrm{ml} \mathrm{MCP}-1$. The lysis buffer contained $50 \mathrm{mM}$ HEPES buffer, 1\% Triton X-100, $5 \mathrm{mM}$ EDTA, $50 \mathrm{mM}$ sodium chloride, $10 \mathrm{mM}$ sodium pyrophosphate, $50 \mathrm{mM}$ sodium fluoride, $1 \mathrm{mM}$ sodium orthovanadate, and protease inhibitors ( $1 \mathrm{mM}$ phenylmethylsulfonylfluoride $/ 1 \mu \mathrm{M}$ leupeptin/1 $\mu \mathrm{M}$ pepstatin A). Protein was quantified using BCA protein assay (Pierce; Thermo Fisher Scientific, Inc.; cat. no. 23227 ) and crude lysates (25 $\mu \mathrm{g}$ ) were fractionated by $10 \%$ sodium dodecyl sulfate polyacrylamide gel electrophoresis, blotted onto polyvinylidene difluoride (PVDF) membranes, incubated with primary antibodies against mitogen-activated protein kinase (MAPK; Cell Signaling Technology, Inc.; cat. no. 9101) and phosphorylated (p-)MAPK (Cell Signaling Technology, Inc.; cat. no. 9102) or $\beta$-tubulin (Cell Signaling Technology, Inc.; cat. no. 2182) as a loading control, followed by incubation with horseradish peroxidase (HRP)-conjugated secondary antibody (goat anti-rabbit IgG-HRP; Santa Cruz Biotechnology, Santa Cruz, CA, USA; cat. no. cs-2004). For 

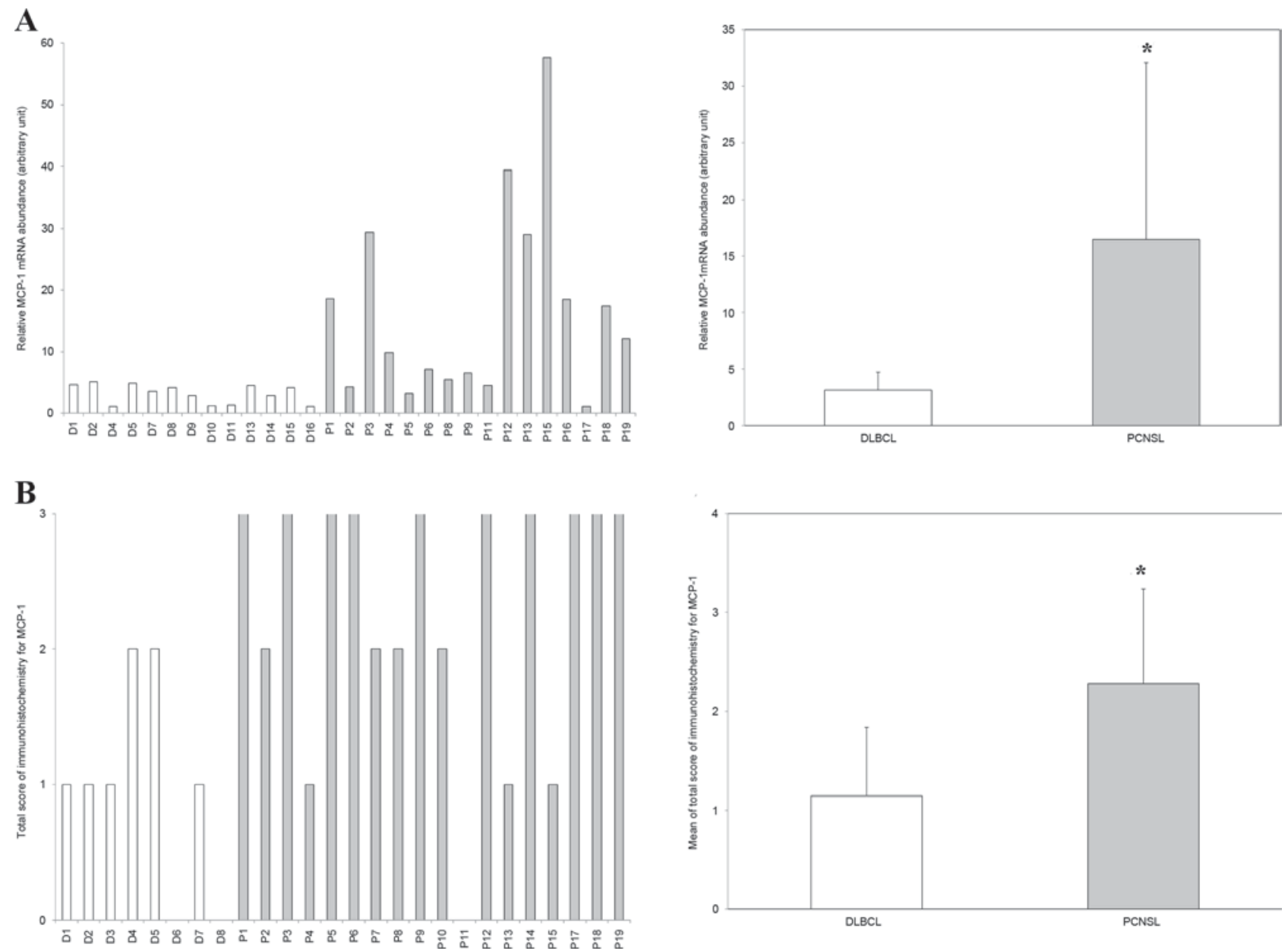

Figure 1. MCP-1 expression in DLBCL and PCNSL. (A) Results of MCP-1 specific reverse transcription-quantitative polymerase chain reaction analysis at the individual level and combined. (B) MCP-1 protein levels, assessed by immunohistochemistry, at the individual level and combined. ${ }^{\mathrm{P}}<0.05$ vs. DLBCL.

immunoblotting analysis, membranes were incubated with diluted antibodies at a dilution of 1:2,000 in TBS buffer including $0.1 \%$ Tween-20 (TBST) with $5 \%$ w/v bovine serum albumin and agitated at $4^{\circ} \mathrm{C}$ overnight. Incubation with TBST including $5 \%$ non-fat dry milk for $1 \mathrm{~h}$ at room-temperature was performed as the blocking step. Membranes were washed with TBST for 10 min three times and incubated with 1:4,000 diluted secondary antibody for $1 \mathrm{~h}$ at room-temperature with agitation, followed by washing with TBST three times. Signals were detected using Immobilon Western Chemiluminescent HRP Substrate (EMD Millipore, Billerica, MA, USA; cat. no. WBKLS0500).

Statistical analysis. The differences between two groups was analyzed using two-tailed Student's t-test. $\mathrm{P}<0.05$ was considered to indicate a statistically significant difference. All statistical analyses were performed using StatView 5.0 software (SAS Institute Inc., Cary, NC, USA).

\section{Results}

MCP-1 expression is upregulated in PCNSL compared with DLBCL. MCP-1-specific RT-qPCR analysis revealed that $M C P-1$ mRNA expression was upregulated $>5$-fold in PCNSL compared with DLBCL ( $<<0.002$; Fig. 1A). Immunohistochemistry also revealed that MCP-1 expression levels trended toward upregulation in PCNSL compared with DLBCL ( $\mathrm{P}=0.002$; Fig. 1B).

TAM infiltration levels are similar in PCNSL and DLBCL. Immunohistochemistry revealed that CD14-positive and CD68-positive TAMs infiltrated into multiple cases of PCNSL and DLBCL. However, there was no difference in the ratio of CD14-positive and CD68-positive TAMs between PCNSL and DLBCL ( $\mathrm{P}=0.18$ and $\mathrm{P}=0.36$, respectively; Fig. 2).

CCR2, a receptor of $M C P-1$, was present in neoplastic PCNSL cells. Immunohistochemical staining with CD20 confirmed that all cases were $B$ cell type lymphoma. Immunofluorescence double staining revealed that the CCR2 signal was concomitant with the cells expressing B cell markers (Fig. 3).

MCP-1 induces MAPK activation in a PCNSL cell model. HKBML cells were stimulated with a dose of MCP-1 (300 ng/ml). MCP-1 induced tyrosine phosphorylation of MAPK, as assessed by western blot analysis with a maximum activation observed at $30 \mathrm{~min}$ (Fig. 4A).

MCP-1 increased cell proliferation in PCNSL model. To assess the effect of MCP-1 on PCNSL cell proliferation, HKBML cells were stimulated with increasing concentrations of MCP-1. HKBML cells demonstrated increased proliferation 

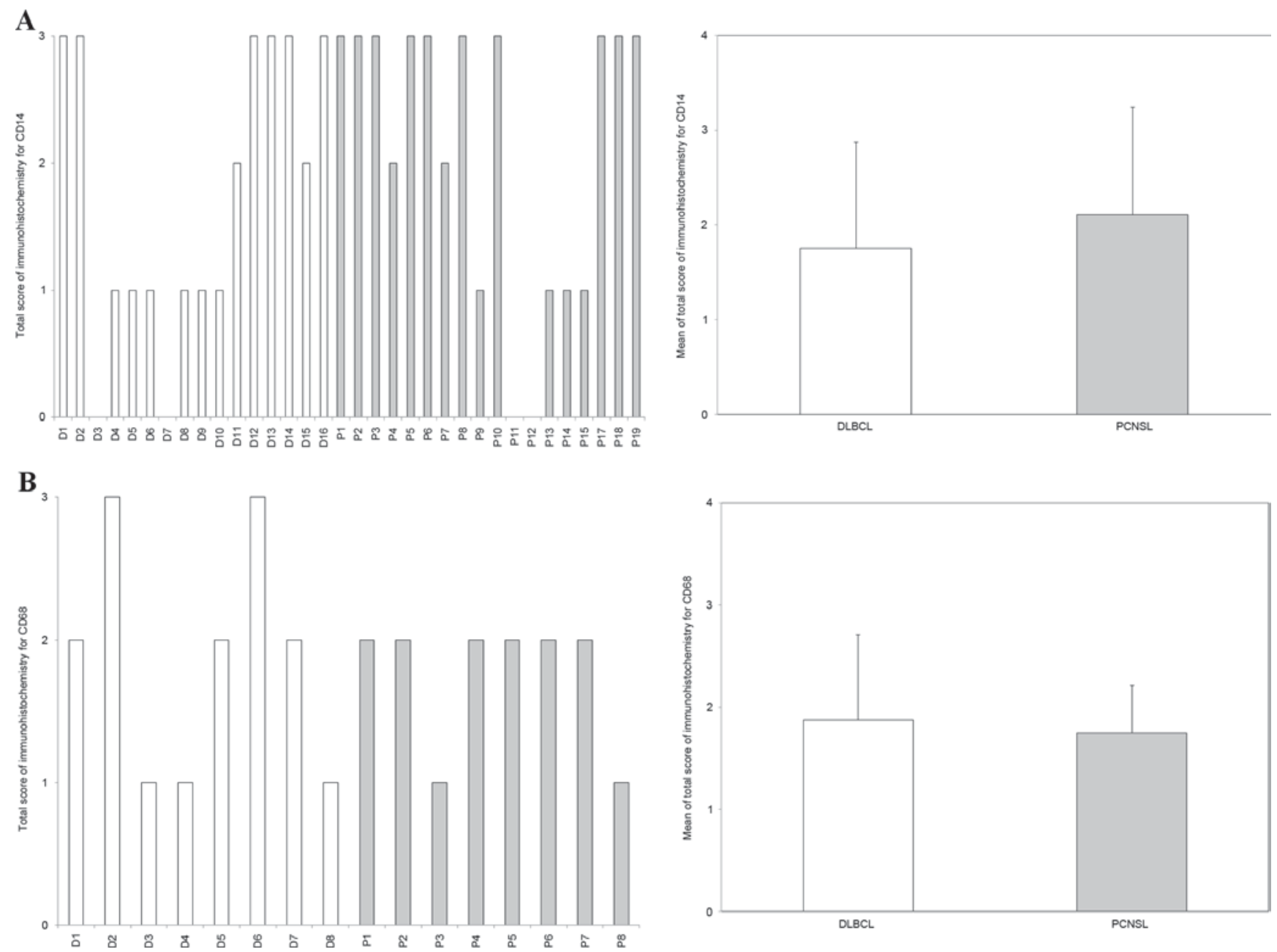

Figure 2. Infiltration level of tumor-associated macrophages in PCNSL and DLBCL, as assessed by immunohistochemical staining for CD14 and CD68. (A) Individual and combined total scores of CD14 staining in DLBCL and PCNSL. (B) Individual and combined total scores of CD68 staining in DLBCL and PCNSL. PCNSL, primary central nervous system lymphoma; DLBCL, diffuse large B cell lymphoma; CD, cluster of differentiation.
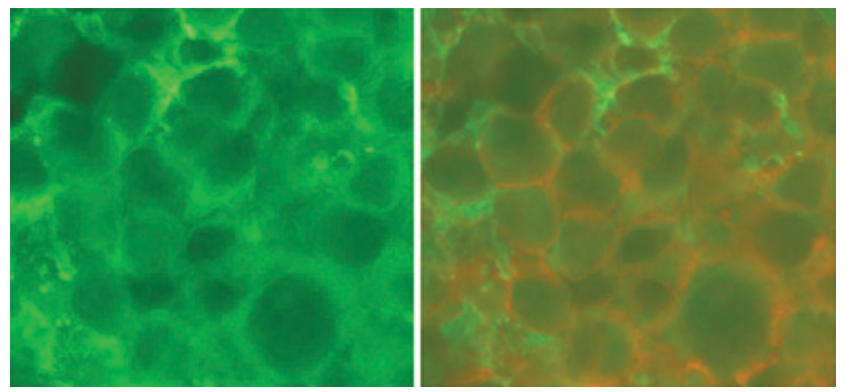

Figure 3. A representative, immunostained primary central nervous system lymphoma section, revealing the presence of CCR2 (green) and cluster of differentiation 20 (red) at the cell surface (magnification, $x 400)$. Thus, CCR2 expression in tumor cells was confirmed. CCR2, C-C motif chemokine receptor 2 .

in response to MCP-1 compared with the untreated control, with maximum proliferation increase observed at a dose of $500 \mathrm{ng} / \mathrm{ml}$ (Fig. 4B).

\section{Discussion}

In the present study, MCP-1 mRNA and protein expression was demonstrated to be significantly upregulated in PCNSL compared with DLBCL. To the best of our knowledge, there are no previous reports comparing $\mathrm{MCP}-1$ expression between these lymphomas. Although the number of cases used in the present study was limited, the results may be associated with the differences in biological characteristics between PCNSL and DLBCL.

Because a well-known function of MCP-1 is TAM recruitment, the degree of TAM infiltration was confirmed in each type of lymphoma by immunohistochemistry, using CD14 and CD68 as TAM markers. Notably, the degree of TAM infiltration did not differ between the types of lymphoma. In multiple tumor types, the level of CD68-positive TAM infiltration has been demonstrated to be of significant prognostic value (21,25-27). On the other hand, the results of studies concerning the prognostic correlation between the level of infiltration of TAMs and DLBCL was not consistent. Hasselblom et al (11) demonstrated that it was not possible to predict clinical outcomes in DLBCL by evaluating CD68-positive TAM concentration (11), whereas other studies revealed that high TAM density was significantly associated with poor prognosis (13) and worse response to therapy (12). Two additional studies demonstrated that TAMs in PCNSL were not correlated with overall survival $(14,15)$. Thus, there is a possibility that MCP-1 serves a function other than infiltrating TAMs in PCNSL. 
A

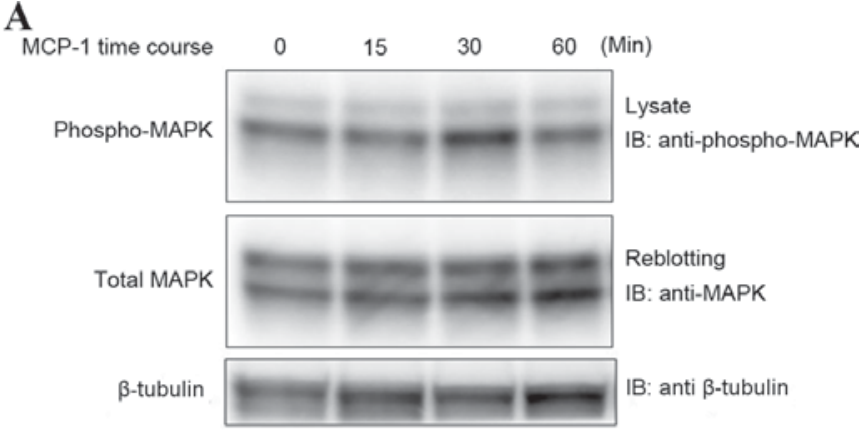

B

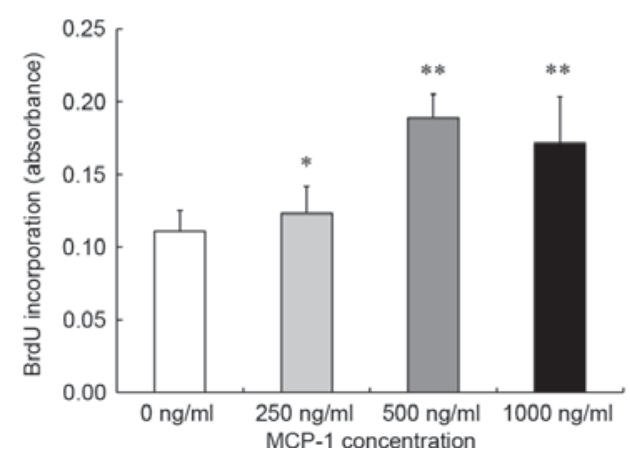

Figure 4. MCP-1-specific activation of MAPK and increased proliferation in HKBML cells and proliferation of HKBML cells in response to MCP-1. (A) Tyrosine phosphorylation of MAPK in response to MCP-1 in HKBML cells, as assessed by western blotting. (B) HKBML cell proliferation in response to increasing doses of MCP-1, as assessed by BrdU assay. Data are expressed as the mean \pm standard deviation. ${ }^{*} \mathrm{P}<0.02$ and ${ }^{* * *} \mathrm{P}<0.0001$ vs. $0 \mathrm{ng} / \mathrm{ml}$ control $(\mathrm{n}=20)$. MCP-1, monocyte chemoattractant protein 1 ; MAPK, mitogen-activated protein kinase; BrdU, 5-bromo-2'-deoxyuridine; IB, immunoblotting.

Hence, the present study hypothesized that MCP-1upregulated lymphoma, PCNSL, may produce and maintain MCP-1. The MCP-1 receptor, CCR2, has been reported to mediate the action of the mitogen-activated protein kinase kinase/extracellular signal-regulated kinase and phosphoinositide 3-kinase-protein kinase B pathways when activated by MCP-1, which has been implicated in cell proliferation and survival (28). There are no reports supporting an autocrine function for MCP-1 in PCNSL. To evaluate the hypothesis, PCNSL was confirmed to express CCR 2 by double immunohistochemistry. The results implied that the MCP-1/CCR2 axis functioned in an autocrine manner in PCNSL, which appeared to worsen the prognosis.

Therefore, the autocrine signaling mechanisms by which MCP-1 acts in HKBML cells derived from PCNSL were investigated. MAPK signal transduction pathways are involved in the regulation of cell proliferation. The present study confirmed that MCP-1 induced MAPK phosphorylation in HKBML cells, and further demonstrated that MCP-1 increased MAPK phosphorylation in HKBML cells. Next, to assess the effects of MCP-1 on PCNSL cell proliferation, HKBML cells were stimulated with MCP-1. HKBML cell proliferation increased in response to increasing doses of MCP-1. These results implied that upregulation of MCP-1 expression mediated the augmentation of tumor cell proliferation in PCNSL in an autocrine manner, which appeared to worsen prognosis.
There were several limitations to the present study. First, the number of patients with PCNSL and DLBCL enrolled in the present study was small. PCNSL is rare disease and the amount of tumor tissue obtained by biopsy or surgery is limited. Cooperation among multiple hospitals was therefore necessary for the present study. Second, the association between patient survival and MCP-1 expression was not investigated because the therapies used to treat patients were different between the hospitals. Third, the relationships between signaling pathways other than MAPK and MCP-1 were not evaluated.

In future studies, the effects of abolishing MCP-1 activity using MCP-1 antibodies should be confirmed in a PCNSL cell line. In addition, the association between prognosis and MCP-1 expression should be investigated in a larger number of patients. By further understanding the function of MCP-1 in PCNSL, it may be possible to develop novel strategies to treat patients with PCNSL.

In conclusion, the results of the present study indicated that MCP-1 expression in PCNSL promoted cell proliferation in an autocrine manner.

\section{Acknowledgements}

The human brain-derived lymphoma cell line, HKBML was provided by Riken BioResource Center (Tsukuba, Japan). The authors would like to thank Mrs. Masayo Obata (Department of Neurosurgery, Graduate School of Medical Science, Kumamoto University) for assisting with the immunohistochemistry.

\section{References}

1. Olson JE, Janney CA, Rao RD, Cerhan JR, Kurtin PJ, Schiff D, Kaplan RS and O'Neill BP: The continuing increase in the incidence of primary central nervous system non-Hodgkin lymphoma: A surveillance, epidemiology, and end results analysis. Cancer 95: 1504-1510, 2002.

2. Prodduturi P and Bierman PJ: Current and emerging pharmacotherapies for primary CNS lymphoma. Clin Med Insights Oncol 6: 219-231, 2012.

3. Bingle L, Brown NJ and Lewis C: The role of tumour-associated macrophages in tumour progression: Implications for new anticancer therapies. J Pathol 196: 254-265, 2002.

4. Mantovani A, Sozzani S, Locati M, Allavena P and Sica A: Macrophage polarization: Tumor-associated macrophages as a paradigm for polarized M2 mononuclear phagocytes. Trends Immunol 23: 549-555, 2002.

5. Pollard JW: Tumour-educated macrophages promote tumour progression and metastasis. Nat Rev Cancer 4: 71-78, 2004.

6. Komohara Y, Jinushi M and Takeya M: Clinical significance of macrophage heterogeneity in human malignant tumors. Cancer Sci 105: 1-8, 2014.

7. Ding P, Wang W, Wang J, Yang Z and Xue L: Expression of tumor-associated macrophage in progression of human glioma. Cell Biochem Biophys 70: 1625-1631, 2014.

8. Komohara Y, Horlad H, Ohnishi K, Fujiwara Y, Bai B, Nakagawa T, Suzu S, Nakamura H, Kuratsu J and Takeya M: Importance of direct macrophage-tumor cell interaction on progression of human glioma. Cancer Sci 103: 2165-2172, 2012.

9. Komohara Y, Hasita H, Ohnishi K, Fujiwara Y, Suzu S, Eto M and Takeya M: Macrophage infiltration and its prognostic relevance in clear cell renal cell carcinoma. Cancer Sci 102: 1424-1431, 2011.

10. Komohara Y, Niino D, Saito Y, Ohnishi K, Horlad H, Ohshima K and Takeya M: Clinical significance of CD163+ tumor-associated macrophages in patients with adult T-cell leukemia/lymphoma. Cancer Sci 104: 945-951, 2013. 
11. Hasselblom S, Hansson U, Sigurdardottir M, Nilsson-Ehle H, Ridell B and Andersson PO: Expression of CD68+ tumor-associated macrophages in patients with diffuse large B-cell lymphoma and its relation to prognosis. Pathol Int 58: 529-532, 2008.

12. Cai QC, Liao H, Lin SX, Xia Y, Wang XX, Gao Y, Lin ZX, Lu JB and Huang HQ: High expression of tumor-infiltrating macrophages correlates with poor prognosis in patients with diffuse large B-cell lymphoma. Med Oncol 29: 2317-2322, 2011.

13. Wada N, Zaki MA, Hori Y, Hashimoto K, Tsukaguchi M, Tatsumi Y, Ishikawa J, Tominaga N, Sakoda H, Take H, et al Tumour-associated macrophages in diffuse large B-cell lymphoma: A study of the osaka lymphoma study group. Histopathology 60: 313-319, 2012.

14. Komohara Y, Horlad H, Ohnishi K, Ohta K, Makino K, Hondo H, Yamanaka R, Kajiwara K, Saito T, Kuratsu J and Takeya M: M2 macrophage/microglil cells induce activation of Stat3 in primary central nervous system lymphoma. J Clin Exp Hematop 51: 93-99, 2011.

15. Sasayama T, Tanaka K, Mizowaki T, Nagashima H, Nakamizo S, Tanaka H, Nishihara M, Mizukawa K, Hirose T, Itoh T and Kohmura E: Tumor-associated macrophages associate with cerebrospinal fluid interleukin-10 and survival in primary central nervous system lymphoma (PCNSL). Brain Pathol 26: 479-487, 2016.

16. Jiménez-Sainz MC, Fast B, Mayor F Jr and Aragay AM: Signaling pathways for monocy te chemoattractant protein 1-mediated extracellular signal-regulated kinase activation. Mol Pharmacol 64: 773-782, 2003

17. Johnson Z, Power CA, Weiss C, Rintelen F, Ji H, Ruckle T, Camps M, Wells TN, Schwarz MK, Proudfoot AE and Rommel C: Chemokine inhibition - why, when, where, which and how? Biochem Soc Trans 32: 366-377, 2004.

18. Mellado M, Rodríguez-Frade JM, Aragay A, del Real G, Martín AM, Vila-Coro AJ, Serrano A, Mayor F Jr and Martínez-A C: The chemokine monocyte chemotactic protein 1 triggers Janus kinase 2 activation and tyrosine phosphorylation of the CCR2B receptor. J Immunol 161: 805-813, 1998.
19. Balkwill $\mathrm{F}$ and Mantovani A: Inflammation and cancer: Back to Virchow? Lancet 357: 539-545, 2001.

20. Conti I and Rollins BJ: CCL2 (monocyte chemoattractant protein-1) and cancer. Semin Cancer Biol 14: 149-154, 2004.

21. Fujiwara T, Fukushi J, Yamamoto S, Matsumoto Y, Setsu N, Oda Y, Yamada H, Okada S, Watari K, Ono M, et al: Macrophage infiltration predicts a poor prognosis for human ewing sarcoma. Am J Pathol 179: 1157-1170, 2011.

22. Loberg RD, Day LL, Harwood J, Ying C, St John LN, Giles R, Neeley CK and Pienta KJ: CCL2 is a potent regulator of prostate cancer cell migration and proliferation. Neoplasia 8: 578-586, 2006.

23. Kitai R, Ishisaka K, Sato K, Sakuma T, Yamauchi T, Imamura Y, Matsumoto $\mathrm{H}$ and Kubota T: Primary central nervous system lymphoma secretes monocyte chemoattractant protein 1 . Med Mol Morphol 40: 18-22, 2007.

24. Livak KJ and Schmittgen TD: Analysis of relative gene expression data using real-time quantitative PCR and the 2(-Delta Delta C(T)) method. Methods 25: 402-408, 2001.

25. Steidl C, Lee T, Shah SP, Farinha P, Han G, Nayar T, Delaney A, Jones SJ, Iqbal J, Weisenburger DD, et al: Tumor-associated macrophages and survival in classic Hodgkin's lymphoma. N Engl J Med 362: 875-885, 2010.

26. Takayama H, Nishimura K, Tsujimura A, Nakai Y, Nakayama M, Aozasa K, Okuyama A and Nonomura N: Increased infiltration of tumor associated macrophages is associated with poor prognosis of bladder carcinoma in situ after intravesical bacillus Calmette-Guerin instillation. J Urol 181: 1894-1900, 2009.

27. Tan KL, Scott DW, Hong F, Kahl BS, Fisher RI, Bartlett NL, Advani RH, Buckstein R, Rimsza LM, Connors JM, et al: Tumor-associated macrophages predict inferior outcomes in classic Hodgkin lymphoma: A correlative study from the E2496 Intergroup trial. Blood 120: 3280-3287, 2012.

28. Yao H, Peng F, Dhillon N, Callen S, Bokhari S, Stehno-Bittel L, Ahmad OS, Wang JQ and Buch S: Involvement of TRPC channels in CCL2-mediated neuroprotection against tat toxicity. J Neurosci 29: 1657-1669, 2009. 